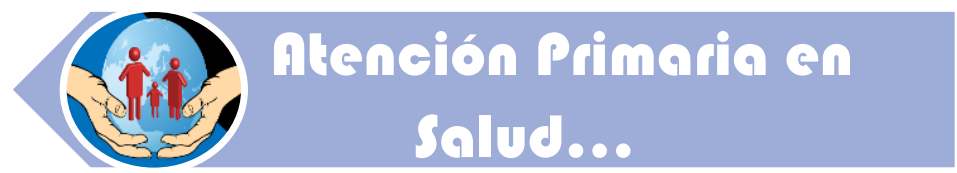

\title{
QǗ DEBEN TENER LOS PROGRAMAS DE PREGRADO EN EL AREA DE LA SALUD
}

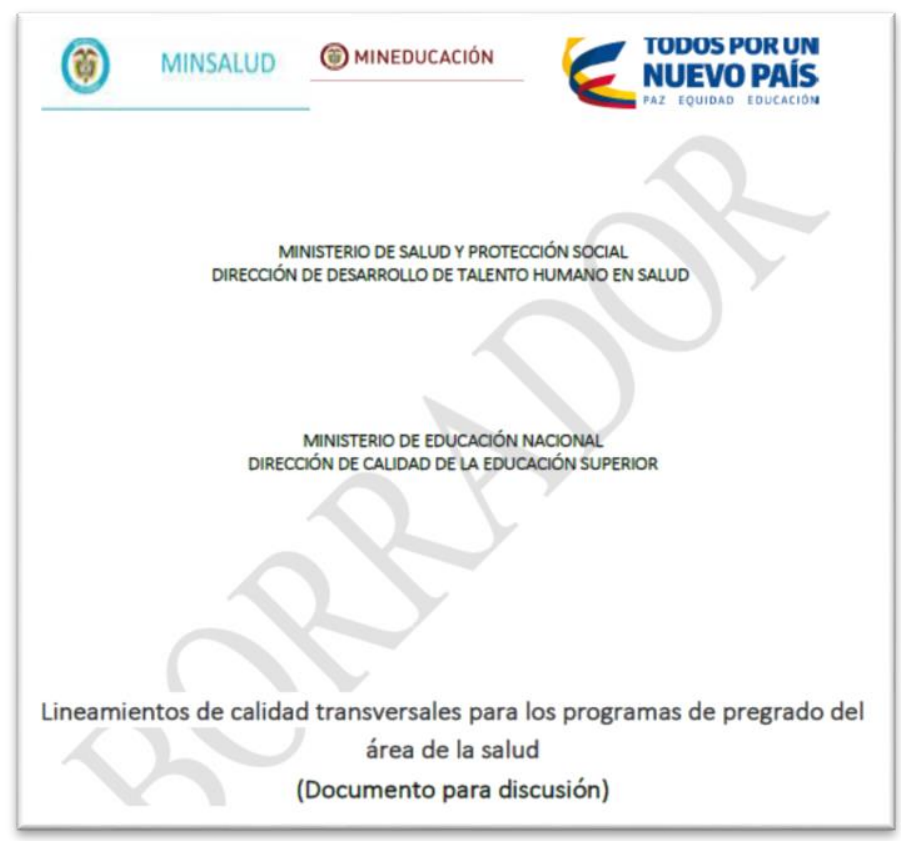

Nos llegó para análisis el documento en borrador para discusión "Lineamientos de calidad transversales para los programas de pregrado del área de la salud". Considerando tal documento clave pues de ahí surgirán pautas, consideramos importante darlo a conocer y aportar algunos comentarios, por supuesto que a título personal.

\section{La descripción del documento}

El documento está compuesto por una introducción donde se pone de explica la importancia de saber qué se va enseñar en la educación superior.

El primer capítulo ofrece un panorama del crecimiento de las profesiones de la salud, en particular enfermería. Luego menciona la prelación de los escenarios clínicos como sitios de práctica. Continúa con un análisis cuantitativo de dichos escenarios.

El segundo capítulo pone de manifiesto la importancia de formar para cumplir con el anhelo de lograr la Política de Atención Integral de Salud. Sigue con una mención del Sistema Nacional de Calidad de la Educación Terciaria. Luego menciona lo que son las competencias, cómo aseguran la calidad de la educación superior y cómo se entregan los registros calificados, finalizando con la forma como evalúan la pertinencia de los programas de salud. 


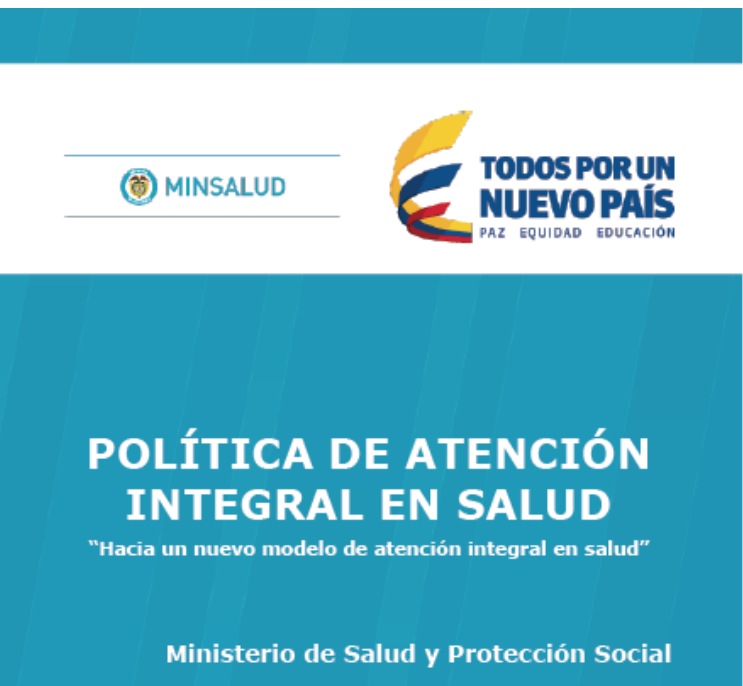

El tercer capítulo revisa las condiciones específicas de calidad de los programas de salud. Finaliza con unas conclusiones.

\section{Introducción}

Menciona el documento que sin duda la educación debe responder a la problemática que la sociedad enfrenta y ser una respuesta para buscar soluciones. Por ende, la educación debe ser consciente del momento que los países viven. ¿Qué enseñar? Es el reto de las universidades, donde la pertinencia de ese conocimiento es clave. Claro, el proceso pedagógico estará centrado en el estudiante.

\section{Lo que en toda educación debe promoverse}

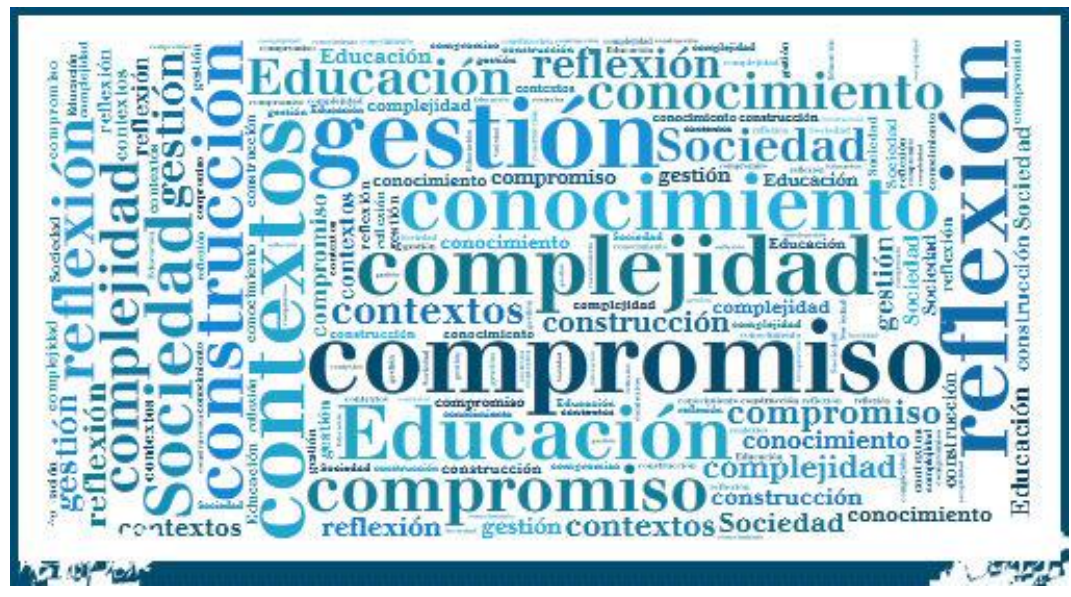

https://fernandonapoli.files.wordpress.com/2013/01/compromiso.jpg

Menciona el documento estos cinco aspectos:

1. La adquisición de conocimientos prácticos.

2. Competencias y aptitudes para la comunicación.

3. El análisis creativo y crítico.

4. La reflexión independiente.

5. El trabajo en equipo en contextos multiculturales. 
Lo anterior asegurando además el reconocimiento de la importancia de "los determinantes ambientales y sociales de la salud". Promueve que una visión que debe enfatizarse es la del "cuidado de la salud" superando aquella de la "enfermedad", la que hasta el momento ha sido el gran dominio.

Compromete a la educación y, por ende, a la universidad con la responsabilidad social, entendida como dar elementos para que sus egresados sepan cómo enfrentar los problemas polifacéticos que vive la sociedad.

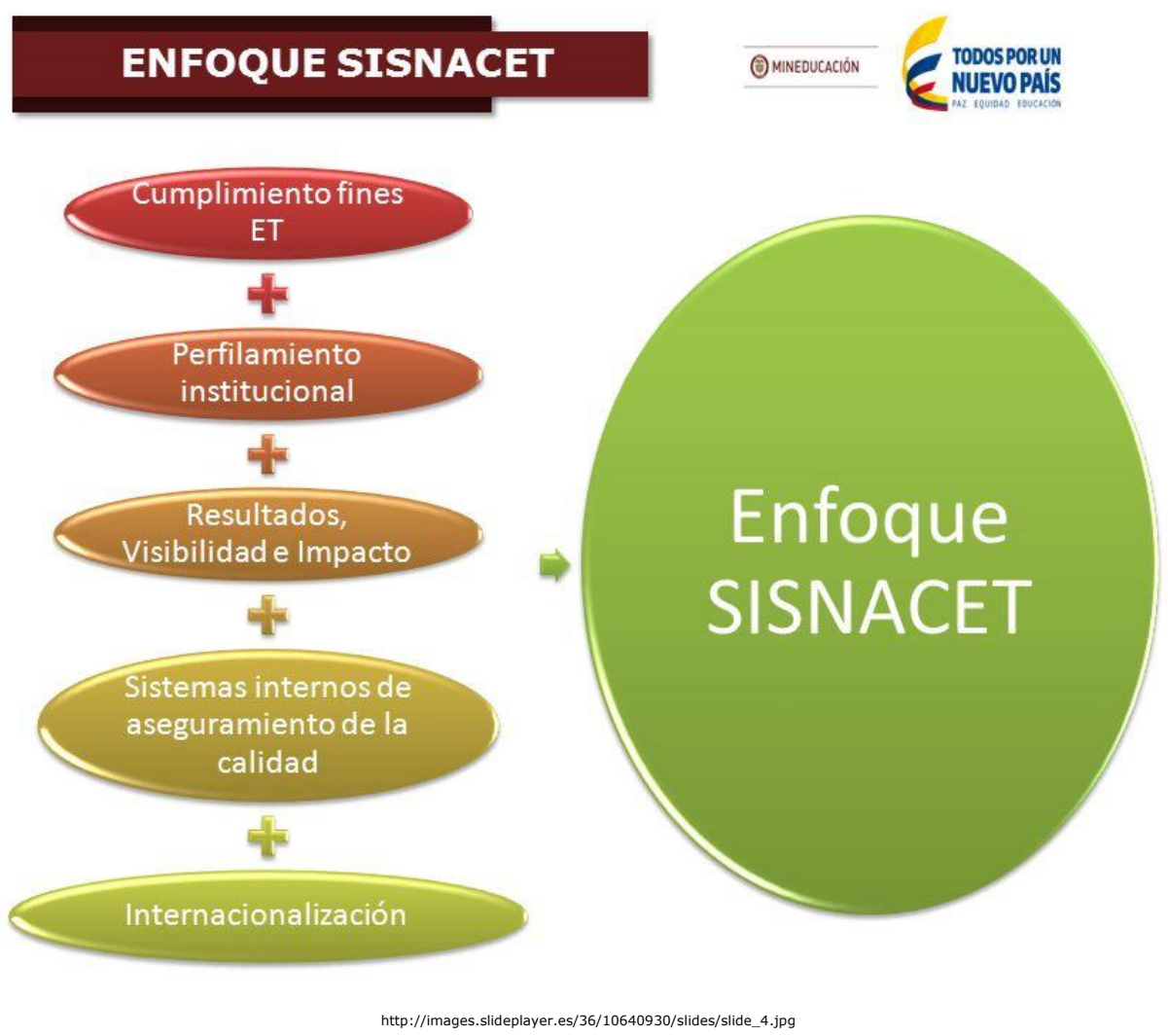

Plantea la necesidad de unir los Ministerios de Educación con el de Salud y Protección Social y, una vez más, insiste en que el proceso educativo aborde la necesidad de favorecer la integralidad de las necesidades de la población y, en tal sentido, la orientación ha de estar dada hacia la Atención Primaria de Salud.

En general, el documento pretende dar los lineamentos para todas las profesiones de pregrado del área de la salud.

\section{Situación actual de la formación y desempeño de los profesionales de la salud en Colombia}

Pone de manifiesto que existen 295000 profesionales de Bacteriología, Enfermería, Fisioterapia, Fonoaudiología, Instrumentación Quirúrgica, Medicina, Nutrición y Dietética, Odontología, Optometría, Psicología, Terapia Ocupacional, Terapia Respiratoria y Química Farmacéutica, cifra que pone de manifiesto cómo en 15 años el número se duplicó. 


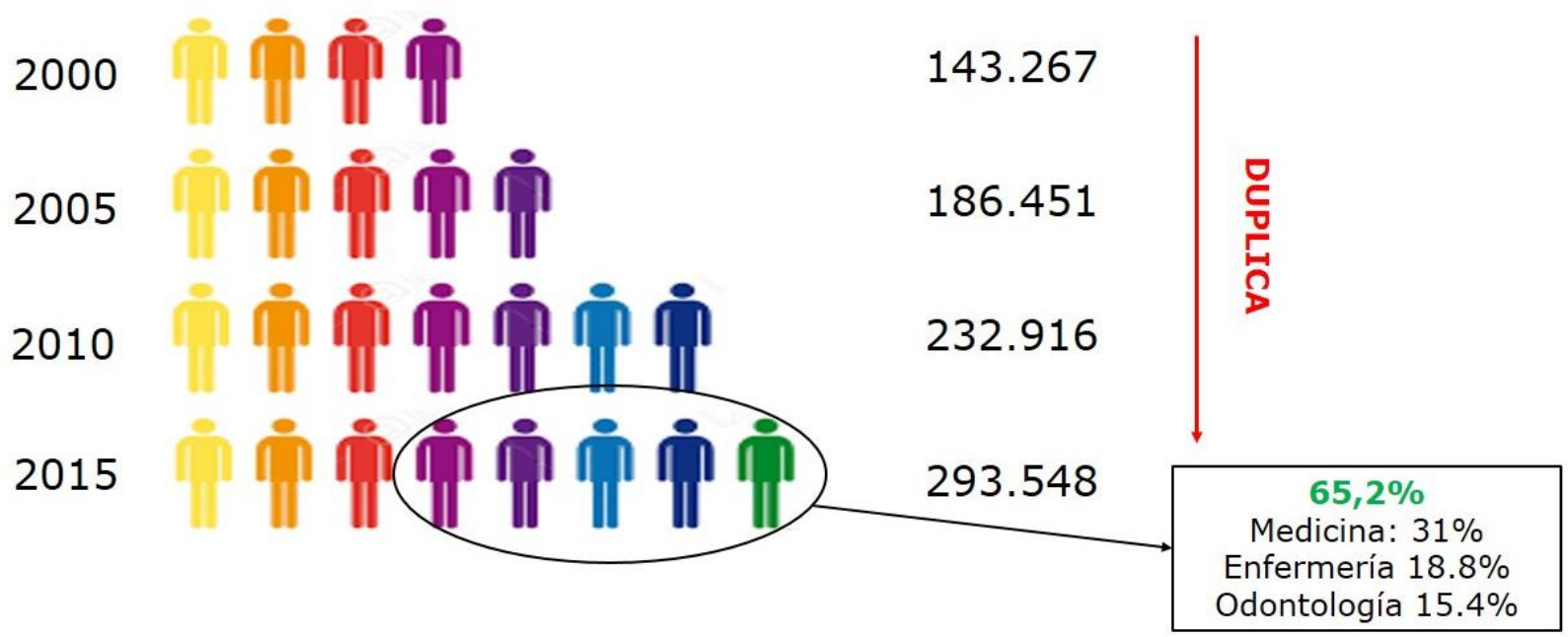

Disponibilidad de profesionales de la salud, período 2000 - 2015 Ministerio de Salud y Protección Social, 2016.

Dos de tres de este incremento es debido al crecimiento de Medicina (lo que más ha crecido), Enfermería y Odontología. La razón entre enfermeras y médicos está en 0,6 a 1 y el ideal es de 1 a 1 (OMS).

\section{El MIAS}

\section{Modelo Integral de Atención en Salud}

\section{LO QUE QUEREMOS}

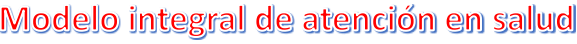

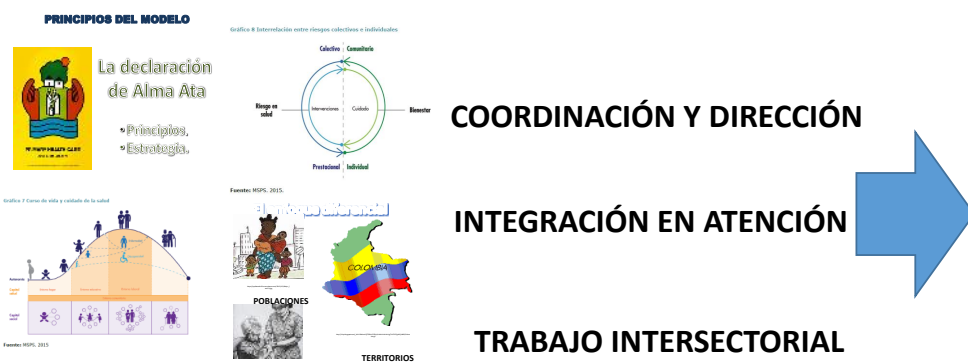

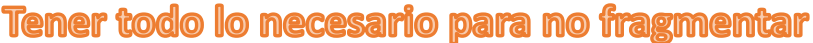

\section{LO QUE DEBE TENER}

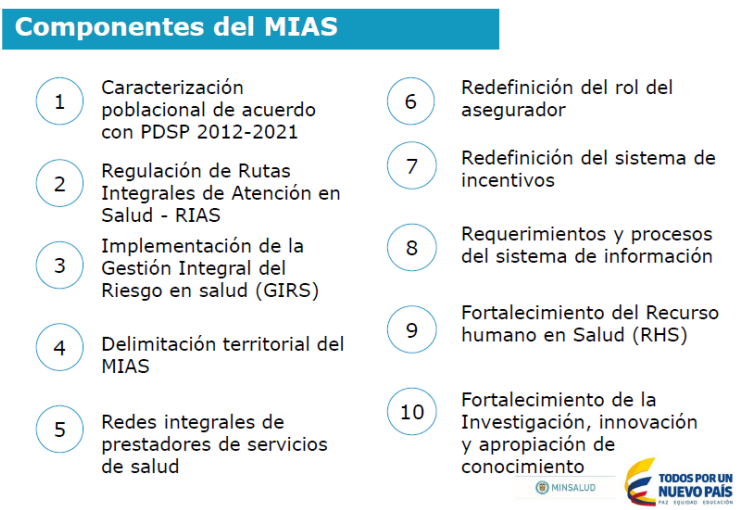

El nuevo Modelo Integral de Atención en Salud se convierte en el referente hacia donde debe ir la formación del recurso humano. 


\section{Los escenarios de práctica}

Si bien la Ley 100 estableció que los escenarios clínicos son los dominantes para la formación, ello se establece a través de Instituciones Prestadoras de Salud (IPS) propias de las Instituciones de Educación Superior (IES) o de los convenios docentes asistenciales. Sin embargo, la mayoría de convenios se hacen con entidades diferentes a IPS, que por su razón, son escenarios donde accede la población que se necesita para la formación de las distintas profesiones.

El documento menciona que la Comisión Nacional Intersectorial de Aseguramiento de la Calidad de la Educación Superior (CONACES) es el encargado de evaluar los escenarios.

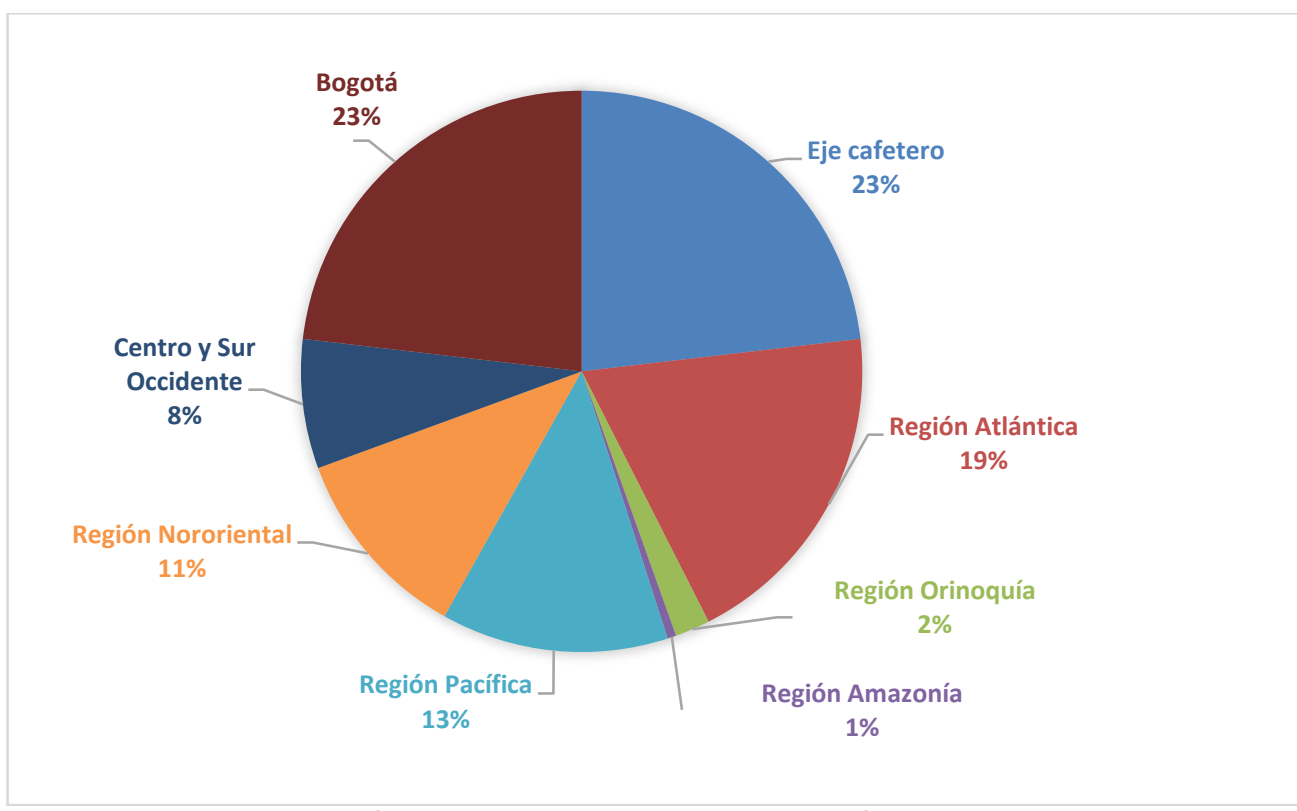

Distribución regional de los escenarios de práctica visitados.

Elaboración propia a partir de la base de datos de escenarios de práctica visitados por el Ministerio de Educación Nacional entre 2015 y 2016.

La gráfica pone de manifiesto los sitios visitados y aprobados por el CONACE en el último año. Reconoce que no es fácil hacer visitas y mucho menos los seguimientos.

\section{El asunto}

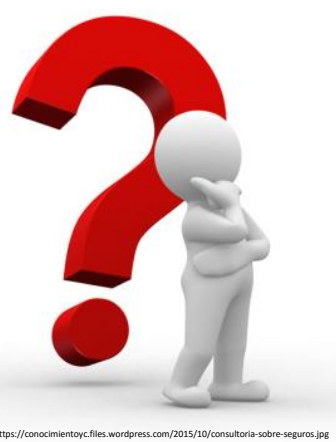

No es fácil evaluar la idoneidad del escenario, aspectos como la cantidad de estudiantes, la relación con docentes en el sitio y la relación camaestudiante, hacen que sea información difícil de verificar, máxime porque la permanencia de los estudiantes puede no ser continua en el sitio. Lo cierto es que existen escenarios subutilizados en tanto otros están sobresaturados. El documento reconoce que no existe un instrumento estandarizado, lo que pone de manifiesto que aún no se sabe con certeza cómo hacer esta valoración. 


\section{Aspectos por mejorar}

Dado que al menos para Medicina y Enfermería los sitios de práctica son IPS de media y alta complejidad, el asunto del consentimiento por parte de los pacientes no está bien abordado.

Se hace evidente que algunas IPS, predomina el cobro económico a las IES más que el beneficio para sus pacientes al momento de hacer los convenios.

En escenarios de práctica de baja complejidad donde no existe vocación docente, se hace difícil evaluar la pertinencia de las prácticas docentes-asistenciales.

Existen escenarios donde las IES "dejan" sus estudiantes sin mayor supervisión docente, lo que evidencia que no existen actividades académicas, siendo la parte asistencial la única presente.

Existen docentes en las IPS que, si bien tienen convenios docentes con las IES, no tienen formación pedagógica.

Existen sitios de práctica donde no existe proceso de seguimiento a la enseñanza (no se pueden establecer las curvas de aprendizaje).

\section{Marco de política}

\section{Dos son los referentes a tener en cuenta:}

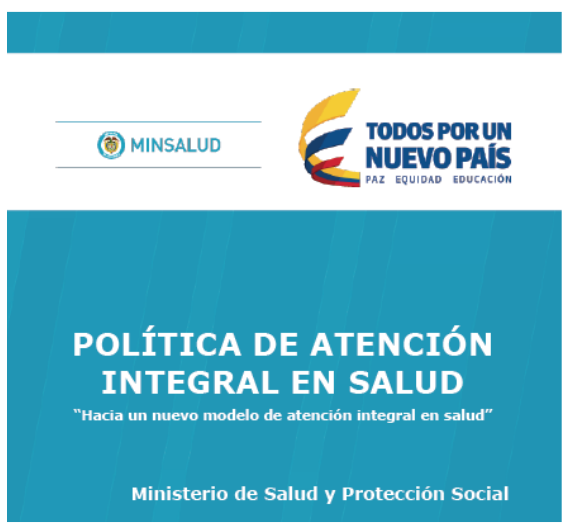

"En el caso del Ministerio de Salud y Protección Social (MSPS), con la Resolución 429 de 2016, se adoptó la Política de Atención Integral de Salud (PAIS), cuyo objetivo es orientar el sistema de salud hacia la generación de las mejores condiciones de la salud de la población mediante la regulación de las condiciones de intervención de los agentes hacia el acceso a los servicios de salud de manera oportuna, eficaz y con calidad para la preservación, el mejoramiento y su promoción".
"En el caso del Ministerio de Educación Nacional, con el Artículo 58 de la Ley 1753 de junio 09 de 2015, se crean los Sistemas Nacionales de Educación y entre ellos el Sistema Nacional de Calidad de la Educación Terciaria (SISNACET), como instancia de integración y coordinación de los organismos, estrategias e instrumentos de educación terciaria, cuyo objeto es asegurar y promover su calidad".

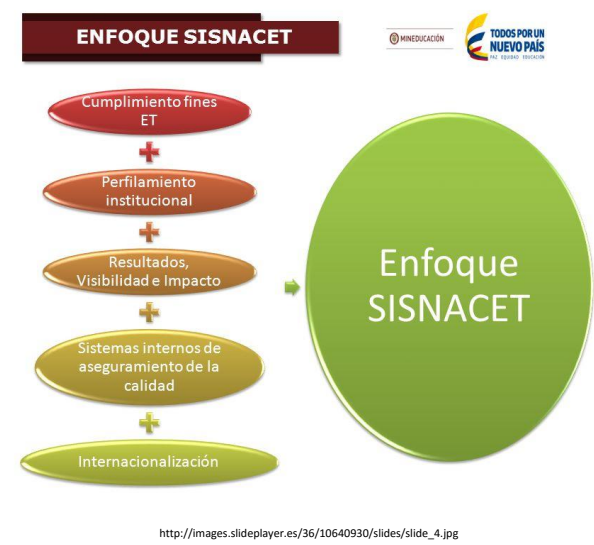




\section{El recurso humano}

En el MIAS, uno de los aspectos fundamentales es precisamente la formación del recurso humano para cumplir su objetivo, reconociendo la necesidad de promover condiciones laborales "decentes".

\section{Hacia dónde debe dirigirse la preparación}
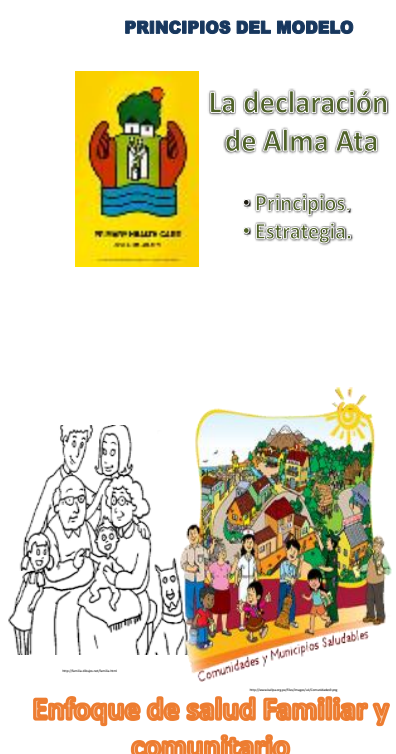
comennitionio
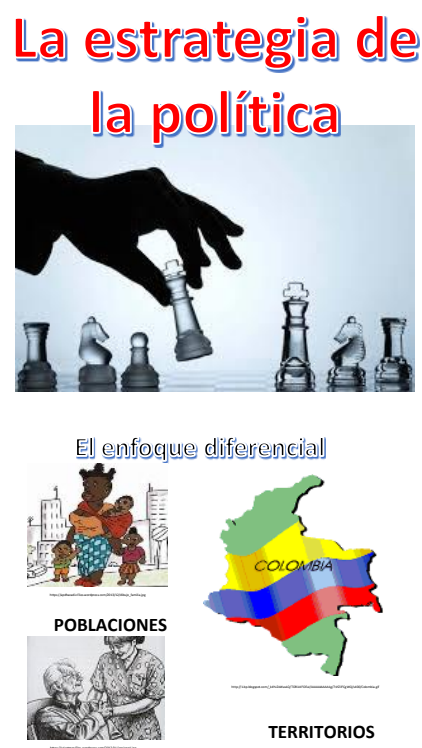

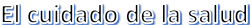
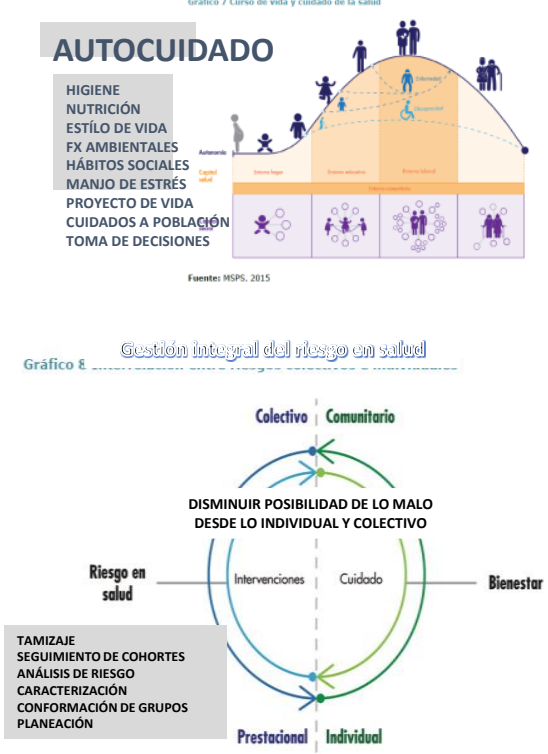

Fuente: MSPS. 2015.

La propuesta del nuevo paradigma es una visión INTEGRAL del ser humano, donde se fortalezca:

1. El cuidado primario de la salud.

2. La prevención y promoción de la salud.

3. Una visión más integral del individuo que contemple a su familia.

Se propuso para ello fortalecer en el posgrado la Medicina Familiar y la Salud Familiar y Comunitaria $y$, en el pregrado, todas las profesiones que se comprometan con dirigir su preparación en este sentido.

\section{El papel del SISNACET}

Asume el reto de reenfocar toda su fuerza impulsar en los programas esta visión de integralidad. 


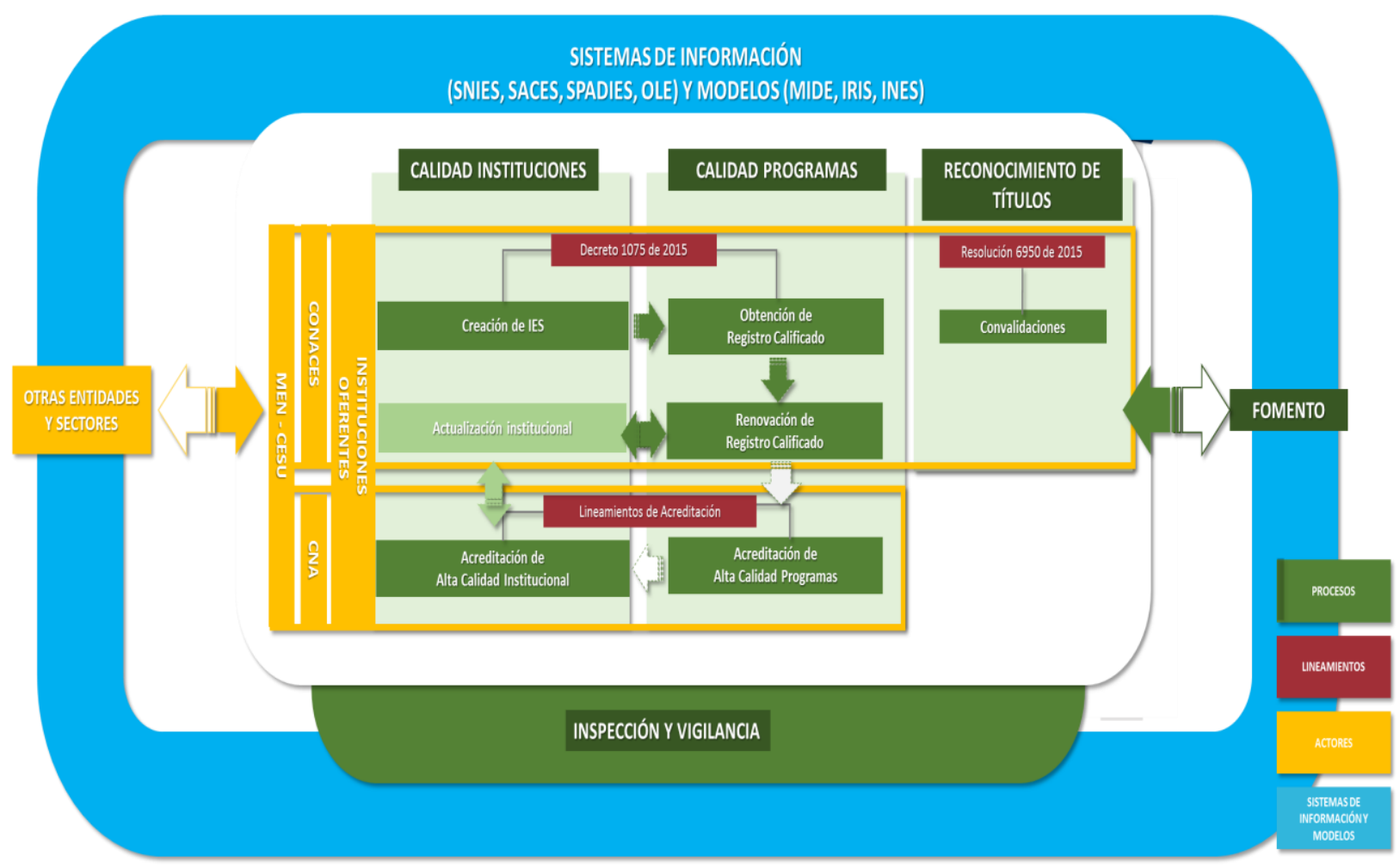

Sistema Nacional de Calidad de la Educación Terciaria.

\section{El gran anhelo}

Se busca fundamentalmente que las IES fortalezcan, como un común para todas las profesiones, las habilidades para hacer posible y real la visión de la Atención Primaria de Salud como el gran reto en la forma de atender a la población.

\section{Las competencias}

Hablan de unas competencias transversales, comunes a todas las profesiones, y son las que nos unen en torno a esa visión del MIAS. En tal sentido proponen para todas las profesiones:

1. Comunicación en lengua materna y en otra lengua internacional.

2. Pensamiento matemático.

3. Cultura científica.

4. Cultura tecnológica.

5. Manejo de la información.

6. Competencias interpersonales y cívicas.

Las específicas dependerán de cada profesión y del contexto que asuman en la salud. 


\section{PROCESO DE REGISTRO CALIFICADO EN SACES}

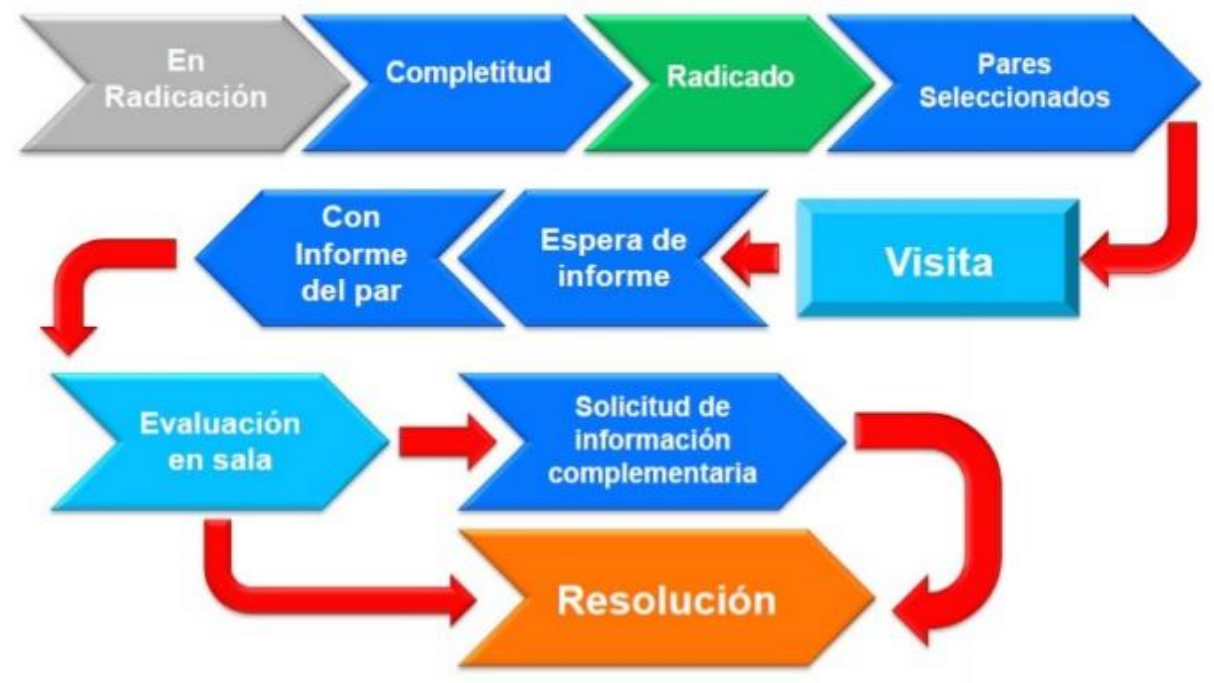

http://image.slidesharecdn.com/registrocalificado-110525105432-phpapp02/95/registro-calificado-9-728.jpg?cb=1306322915

Para tal efecto, la norma consagró estas condiciones de calidad, ocho propias del programa que se pretende ofertar, a saber:

1. Denominación.

2. Justificación.

3. Contenidos curriculares.

4. Organización de actividades académicas.

5. Investigación.

6. Relación con el sector externo.

7. Personal docente.

8. Medios educativos e infraestructura.

$Y$, además, seis condiciones del orden institucional:

9. Mecanismos de selección de estudiantes y docentes.

10. Estructura administrativa y académica.

11. Autoevaluación.

12. Política de egresados.

13. Bienestar universitario.

14. Recursos financieros suficientes, las cuales complementan y dan soporte a la propuesta académica. 


\section{Los pasos}

La IES debe enviar la solicitud (envío de documentación). Si están completos, se hará una visita por parte del CONACES. Clave para la evaluación será encontrar la PERTINENCIA de los programas a través de:

- Denominación.

- Coherencia del programa con los servicios de cuidado de la salud que se prestan en el país.

- Oferta, demanda y suficiencia del talento humano en salud.

- Coherencia del perfil y competencias planteadas por el programa con las necesidades de la población.

\section{¡Pilas con el nombre!}

EI CONACES pondrá especial cuidado a las denominaciones de los programas. Si un programa tiene un mismo nombre, sin importar las IES que lo ofrezcan, debe enseñar en su mayoría lo mismo, ¿cierto?, claro sin descartar aquello que lo hace especial para la identidad de la IES.

\section{Coherencia con el MIAS}

\section{Componentes del MIAS}

1 Caracterización con PDSP 2012-2021

2 Regulación de Rutas Integrales de Atención en Salud - RIAS

(3) Implementación de la

3 Gestión Integral del Riesgo en salud (GIRS) Delimitación territorial del
MIAS

5 Redes integrales de prestadores de servicios de salud

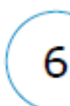

6

7. Redefinición del sistema de

Redefinición del rol del asegurador

\section{incentivos}

8 Requerimientos y procesos del sistema de información

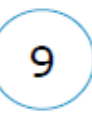

Fortalecimiento del Recurso humano en Salud (RHS)

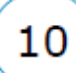

Fortalecimiento de la Investigación, innovación y apropiación de conocimiento

(i) MINSALUD

La forma como los Ministerio de Salud y Educación se han comprometido a impulsar la APS está en que todos los programas contemplen como gran objetivo nacional el Modelo Integral de Atención en Salud. 


\section{Lo que todo programa debe tener para que sea colombiano}

Toda propuesta de formación deberá estar sustentada en la premisa de contribuir a resolver problemas de la población. En tal sentido, y uniéndose a la salud pública, debe tener:

1. Los documentos emitidos por las autoridades sanitarias del lugar de ejecución del programa como los planes territoriales de salud.

2. Los análisis de situación de salud (ASIS) de cada entidad territorial.

3. El Plan Decenal de Salud Pública.

4. El Modelo Integral de Atención en Salud y de esto y en particular:

4.1. Enfoque hacia salud familiar y comunitaria.

4.2. La gestión integral del riesgo.

4.3. El enfoque diferencial a nivel poblacional y territorial y cuidado de la salud.

4.4. Innovaciones hacia los modelos específicos de prestación y gestión de los servicios, desde una perspectiva multidisciplinaria e integral.

El contexto legislativo estará dado en el ofrecimiento del conocimiento sobre el Sistema General de Seguridad Social en Salud, el Sistema Obligatorio de Garantía de la Calidad, el Plan de Intervenciones Colecticas y la Política de Atención Integral en salud.

\section{Los escenarios de práctica}

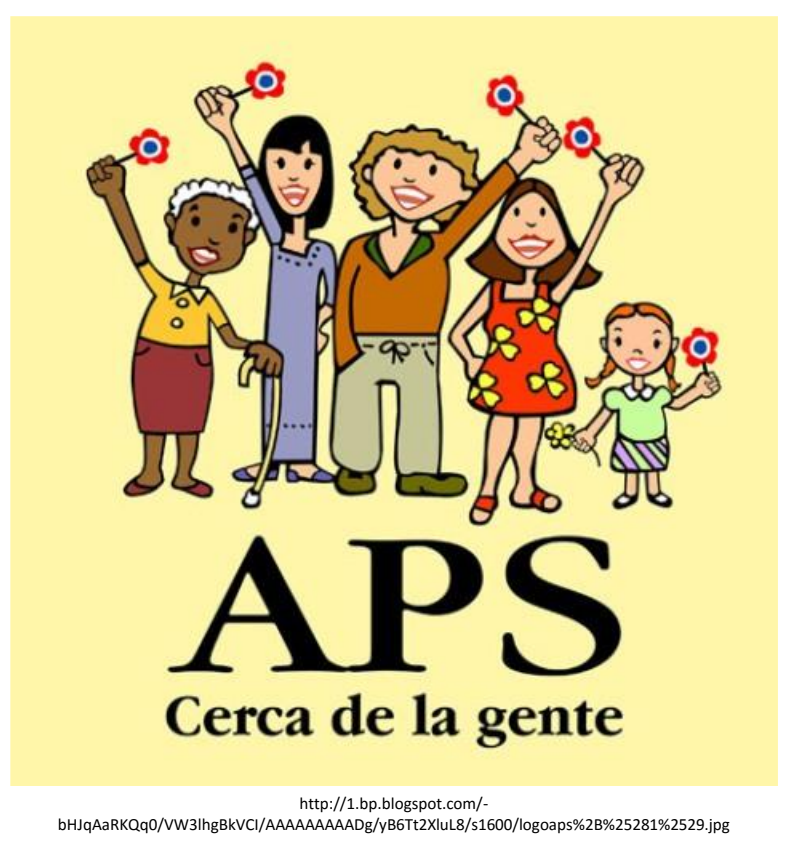

Es clave fortalecer el asunto de la docencia-asistencia en los escenarios de práctica. El sitio, la población a la que se atiende y sus derechos, su relación docente, su capacidad para enseñar y su repercusión en la formación han de ser aspectos a profundizar y donde se deberá buscar criterios que nos acerquen a la deseada calidad. 


\section{iOjo!... Escenarios comunitarios}

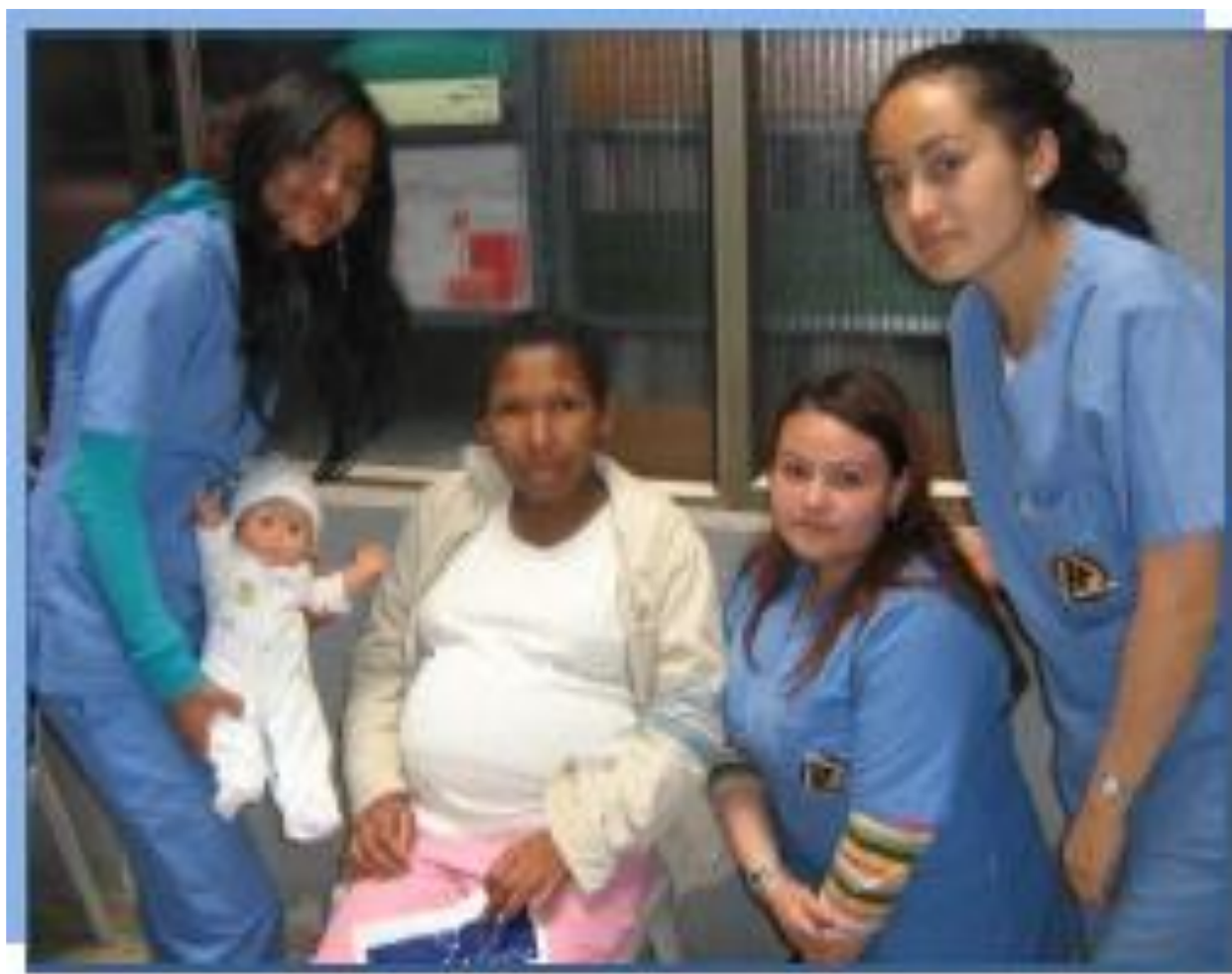

Sin duda la atención en salud se debe enseñar donde está la comunidad. Por ello se deben promover escenarios comunitarios, pero cumpliendo con la calidad educativa esperada. Al respecto, Harzheim y col (2009) anotan lo siguiente:

"Se recomienda la formación...

- En extramuros hospitalarios, en un programa docente-asistencial con integración horizontal y vertical.

- Distritos docente-asistenciales caracterizados por un área geográfica definida, cuya población podría estar adscrita territorialmente a una red de distintos servicios de APS.

- Integrados horizontalmente a la red intersectorial local de servicios públicos y comunitarios.

La integración posibilitaría al alumno una visión del sistema como un todo, comprendiendo el flujo que los usuarios realizan para entender sus necesidades en salud. Los propios alumnos serían como un anillo en la cadena de intervenciones necesarias para mejorar la integración entre los distintos niveles asistenciales.

La interacción activa de alumno con la población y con los profesionales de la salud de forma continua desde el comienzo del proceso de formación, facilitando al alumno el trabajo sobre problemas reales, asumiendo responsabilidades crecientes como agente prestador de cuidado, compatibles siempre son su grado progresivo de autonomía". 


\section{Propuestas}

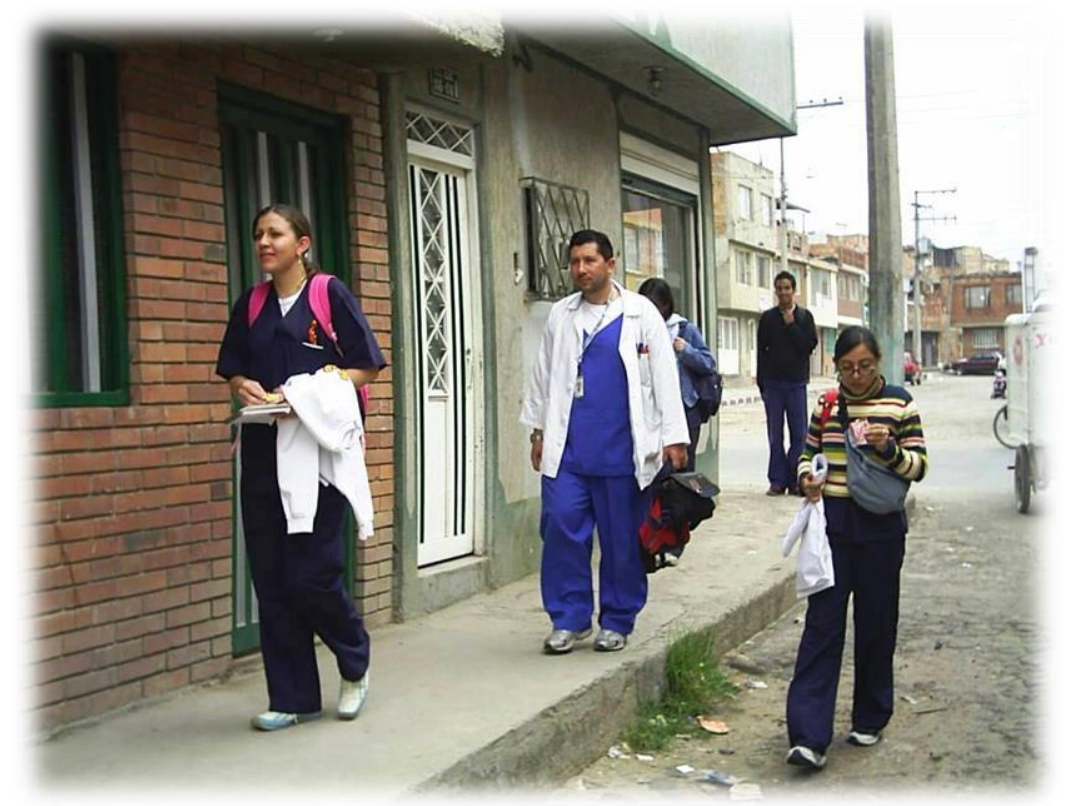

Otras recomendaciones en este sentido son:

Las prácticas formativas en salud deben tener un adecuado balance entre los diferentes niveles de atención, así como en escenarios no clínicos que permitan el desarrollo de competencias para el cuidado de la salud y la atención de la enfermedad en un contexto local, regional y nacional.

Debe existir una asociación estrecha entre el profesorado universitario, la gestión local y los equipos de salud.

Se deben diseñar prácticas que valoricen el contacto horizontal con la población (cuidado longitudinal y continuo) propiciando de esta manera la construcción de vínculos sociales.

Debe existir una red de cooperación entre hospital universitario y red de atención primaria en salud. Se recomienda la capacitación docente tanto en lo disciplinar como en lo pedagógico, favoreciendo la educación continua de los docentes universitarios y de los tutores de la red asistencial.

El apoyo a los docentes, profesores universitarios, tutores y alumnos para que la red de prestadores de servicios de salud y, en especial, el nivel de puerta de entrada, se constituyan en un campo de investigación y producción de conocimiento.

Se debe procurar la centralidad del cuidado como eje temático organizador de las actividades académicas.

Es conveniente la inclusión del trabajo interprofesional en la formación de los profesionales de la salud; debe hacerse tanto en lo teórico como en lo práctico, es decir, en los escenarios clínicos deben existir encuentros multiprofesionales de intervención.

Consolidación de un "centro de salud universitario" para la enseñanza de las profesiones de la salud. Establecimiento de alianzas entre las instituciones formadoras y las IPS para la prestación de servicios de salud con intención formadora; en dicha alianza se deben contemplar las actividades comunitarias y las de promoción, prevención, diagnóstico, tratamiento y rehabilitación; además, se debe considerar un claro lugar para los estudiantes en la prestación de servicios de salud.

Los programas de ciencias de la salud deben lograr que sus estudiantes desarrollen competencias para la realización de informes de la situación de salud de las comunidades y para su interpretación, para el trabajo en equipo y el estímulo a la participación comunitaria; además, competencias en interculturalidad y en pensamiento crítico, investigación, ética y comunicación. 


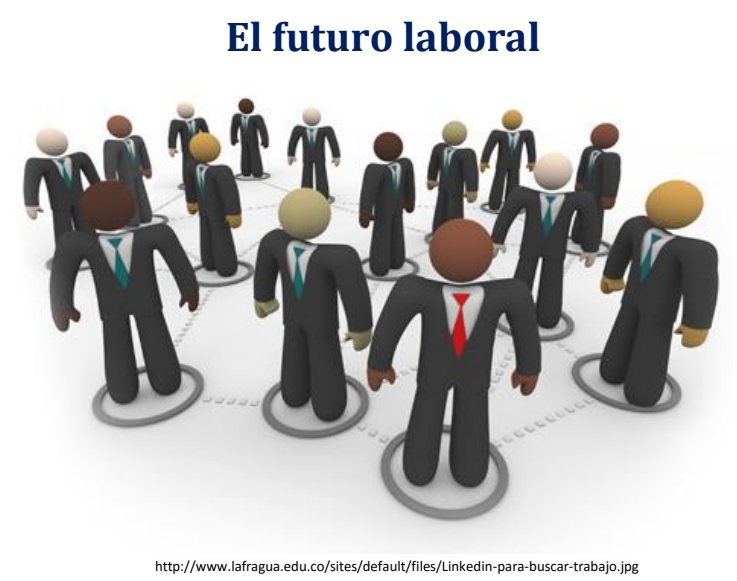

Dice el documento: "La apertura de un nuevo programa educativo, carecerá de pertinencia si:

1. Hay exceso de oferta del talento humano que se pretende formar en los ámbitos nacional o territorial y no existen elementos que permitan prever cambios en la demanda que corrijan la situación.

1.1. Lo que implicaría, de un lado, la profundización de situaciones como el desempleo, el subempleo y bajas remuneraciones.

1.2. De otro lado, una utilización ineficiente de los recursos de las familias y de los sistemas educativo y de salud en la formación de un recurso que va a ser subutilizado.

\section{Fijarse en las competencias}

Menciona el documento que es muy importante revisar muy bien las competencias que el programa ofrece y enfrentarlas a la situación laboral y a las necesidades de la población. De ello depende el futuro laboral del egresado.

\section{Condiciones específicas de calidad para los programas}

Proponen que todos los programas se rijan bajo los siguientes principios:

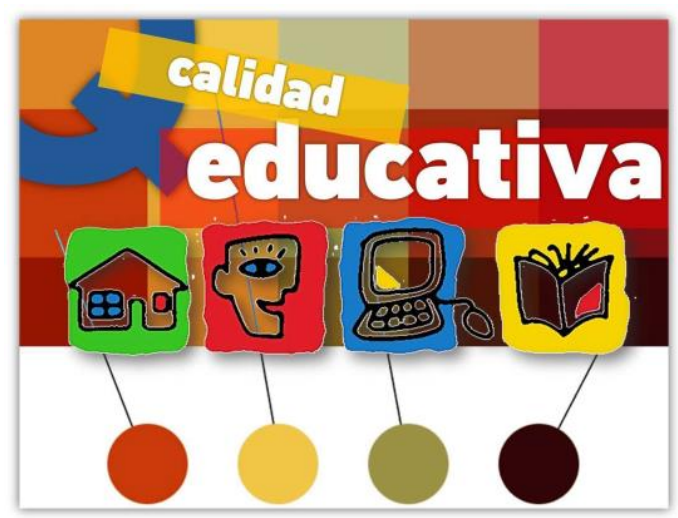

https://centroamericaribeschp.files.wordpress.com/2013/05/calidad-educativa-2.jpg

a. Ética y responsabilidad social, a través de las cuales el programa responda por los derechos de salud de los pacientes y de educación de los estudiantes. 
b. Calidad, asegurando que el programa cumpla tanto con lo académico como con lo administrativo. Los escenarios de práctica son un componente fundamental de esta evaluación.

c. Interculturalidad, entendida como el reconocimiento de la cultura diferencial de acuerdo a región o a posición social con la consiguiente adecuación del conocimiento para lograr su aplicabilidad.

d. Planificación estratégica, a través de la cual, los programas logren impactar no solo a sus estudiantes sino a la población a la que dirigen sus preparación.

e. Autorregulación, por la cual los programas deben analizar el contexto del país y del mismo programa y, con base en eso, regular su profesión.

\section{Denominación}

Es muy importante que el nombre de la carrera sea coincidente para todos (nacional e internacionalmente) y en cualquier IES en torno a lo que significa y para el perfil laboral.

\section{Justificación}

Debe demostrar la forma como el programa responde coherentemente a las necesidades del país. Deben evidenciar su compromiso ético y responsabilidad social con la equidad, el bienestar, el buen vivir y el mejoramiento de la calidad de vida de la población, en relación con los rasgos distintivos del programa. En tal sentido, recordar que hacia dónde se dirige Colombia es hacia la Política de Atención Integral de Salud.

\section{Acciones de obligatorio cumplimiento}

Debe tener estudios de factibilidad. Análisis de situación de salud y la relación e impacto esperado. Por supuesto que debe contemplar la correspondencia entre el programa y el Modelo Integral de Atención en Salud.

\section{Contenidos curriculares y competencias}

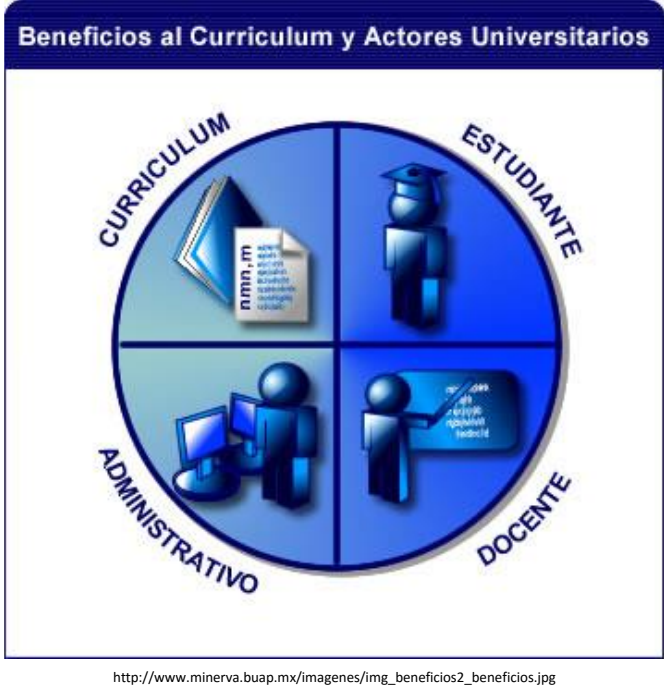

Han de tener una explicación de cómo se logrará una sólida formación científica y técnica. Cómo contribuye a la justicia social. La declaración del componente ético y deontológico. Una descripción de la situación actual y cómo se piensa impactar. Cómo se interrelacionará con los diferentes actores y la forma como abordara la salud de las personas en los diferentes contextos. 


\section{Acciones de obligatorio cumplimiento}

Se propone que todas las profesiones cumplan con las denominadas competencias trasversales, buscando con eso la posibilidad de ese trabajo interdisciplinario. Asimismo, las específicas para todas las áreas de la salud, partiendo que el faro orientador es la Atención Primaria de Salud. De igual forma, el desarrollo de las habilidades para la interculturalidad que permitan acercar las profesiones a la población. Todos los programas han de desarrollar pedagogías que permitan la mejor asimilación por parte de sus estudiantes y construir sus indicadores de desempeño, así como montar una evaluación de sus procesos académicos.

\section{Organización de las actividades académicas}
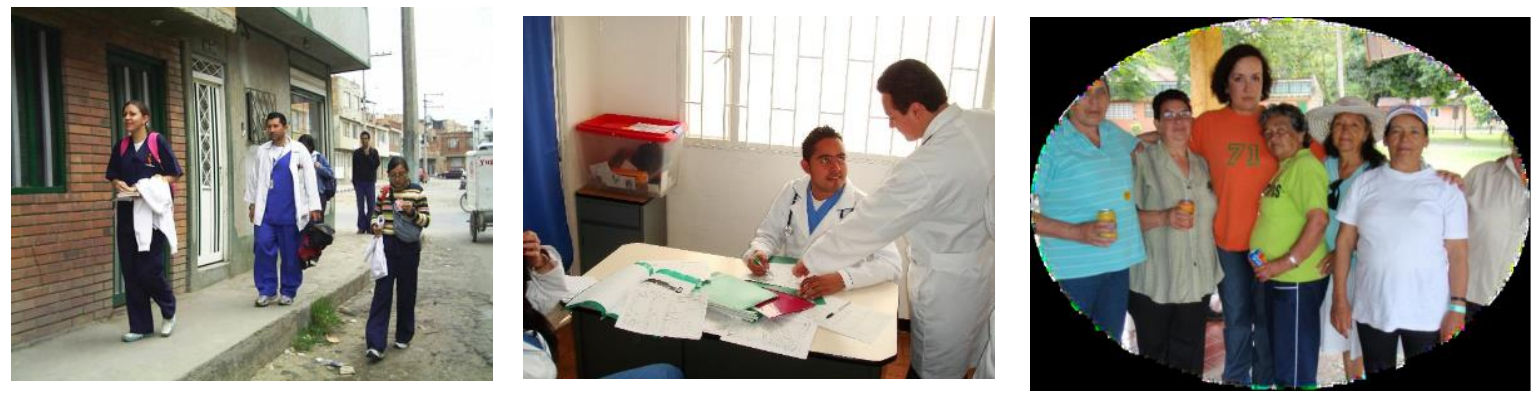

\section{Enseñar salud en la comunidad}
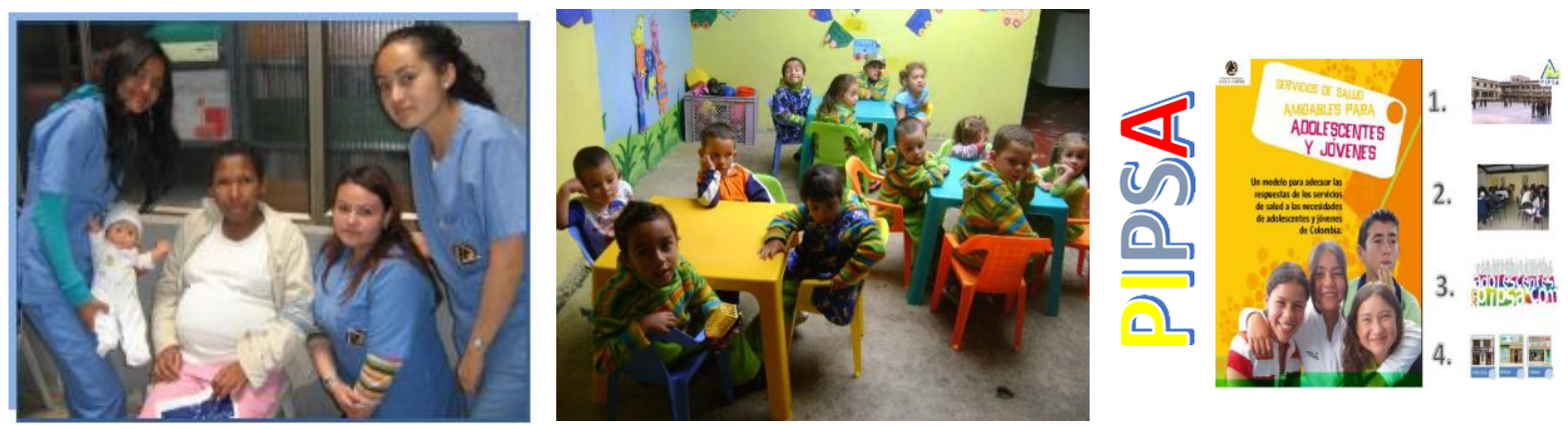

Espacial mención tienen las prácticas formativas por constituirse como la mayor expresión de integralidad. Promueven el vínculo de los estudiantes con la población y la promoción de escenarios comunitarios. Se hace un llamado muy especial a evitar esa relación comercial que pondría en un plano muy diferente el objetivo de los escenarios de práctica (sean clínicos o comunitarios).

\section{Acciones de obligatorio cumplimiento}

El documento propone que el $70 \%$ de las prácticas se realicen en ambientes comunitarios y un $30 \%$ en ambientes clínicos. Promueve la utilización de escenarios virtuales. Propone hacer el cálculo del ideal de número de estudiantes de acuerdo al sitio de práctica. Estimula el acercamiento entre la academia con las redes integrales de servicios de salud. Insiste en definir muy bien la responsabilidad de las IES en los sitios de práctica y la construcción de alianzas estratégicas entre las IES y cada sitio. Censura el pago a los sitios de práctica bajo la visión de "alquiler". Propende por la creación de una 
relación interprofesional con las distintas áreas y profesiones en cada sitio de práctica. Propone llevar las actividades académicas al sitio de práctica.

\section{Acciones de buena práctica}

Incluir como punto fundamental la percepción de la población atendida. Llevar a cabo en cada sitio las razones de las universidades tales como docencia, proyección social e investigación y estimular la formación de equipos multidisciplinarios de aprendizaje.

\section{Personal docente}

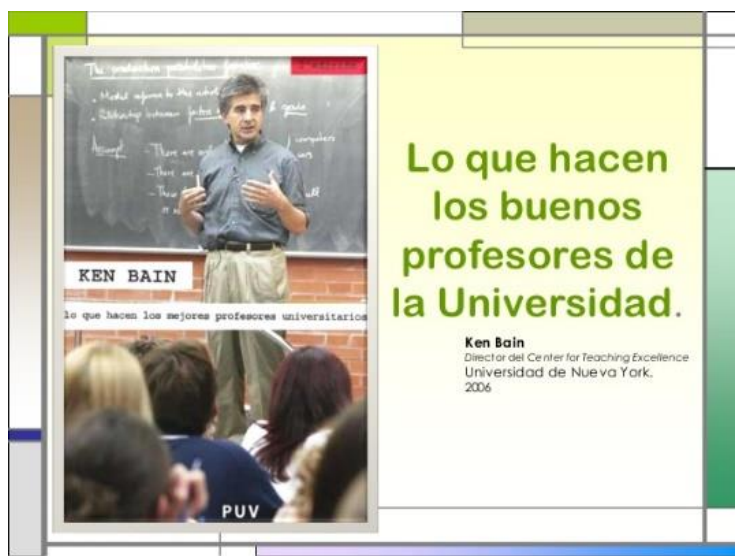

Consideran clave ver la relación docente-estudiantes. Han de tener la preparación pertinente. Se debe propender por la creación de equipos multidisciplinarios. En los sitios de práctica, si se vinculan a personas de allí, ha de hacerse formalmente con su debido reconocimiento. Definir muy bien las responsabilidades y promover la capacitación continua de los docentes. Integrar en lo posible a los docentes de prácticas en los procesos de proyección social e investigación (integración misional).

\section{Investigación y relación con el sector externo}

Promueven la investigación entendida como el plantear soluciones a la realidad encontrada en los escenarios de práctica y que se concluye que refleja o conviven con la realidad nacional. Promueve el "meter" en la cabeza de los estudiantes que la investigación está hecha para cambiar realidades que así lo ameritan. En particular propende a que se fortalezca el MIAS. Hacerles seguimiento a las comunidades, conocer sus percepciones, involucrarse con otros sectores, son acciones que se impulsan bajo este punto. Con el fin que no quede etéreo, se propone la asignación de recursos en tiempo para que se lleve a cabo de manera real.

\section{Educación continuada}

De forma especial promueve y estimula la educación continuada y el seguimiento a los egresados para poder identificar en qué se debe fortalecer la formación de las profesiones.

\section{Infraestructura}

El documento expone que la responsabilidad de los sitios de práctica depende directamente de tales sitios, ello sin descartar que a través de los convenios docente-asistenciales se ofrezca algún apoyo. Lo cierto es que considera que ciertamente la IES debe poner cuidado a las condiciones de los sitios de práctica, propendiendo por la mejora para las condiciones docentes asistenciales. 


\section{Medios educativos}

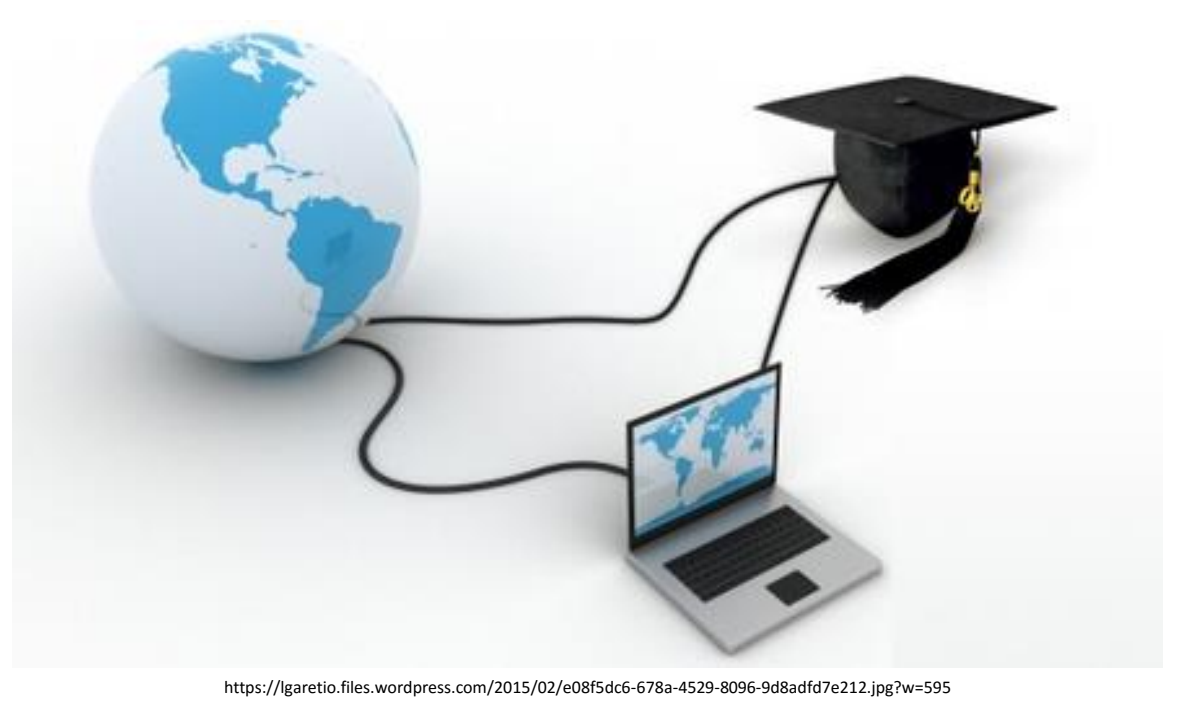

Hace un llamado a estimular la educación virtual como apoyo y aprovechar por completo en las TICS. Estimula el acceso a la información como una competencia transversal, así como la creación de instrumentos de apoyo en las TICS que permitan una obtención de información valiosa que mida en forma ágil para producir acciones. La simulación debe estimularse para crear más escenarios los que sumados, deben producir un estudiante más preparado.

\section{Conclusión}

En síntesis, la propuesta propende la formación de profesionales que tengan al país como prioridad a través de la APS y que esta visión sea el común de todas las profesiones del área de la salud. Los dos Ministerios (Salud y Educación) se están uniendo en tal proyecto, para que los programas sean de la máxima calidad.

\section{Comentario}

Creo, sin lugar a dudas, en la importancia de llevar el proceso de salud y enfermedad a la comunidad. Creo que la prevención, promoción y la rehabilitación se hacen en la comunidad. El hospital está hecho para tratar la enfermedad. Por supuesto que ello es tan importante como la prevención o la rehabilitación; por tanto, la enseñanza práctica ha de hacerse en los dos ambientes: comunidad y hospitales. En ambos es clave el tener los docentes tutores de prácticas. Ellos son diferentes a la concepción de la docencia como clase. Ellos enseñan con el ejemplo y, a través de los grupos de estudiantes que tutorizan, los encargados de enseñar esas habilidades del hacer. Ellos son la clave de la motivación de los estudiantes y los que establecen esos vínculos humanos que tanto queremos promover. 


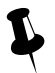

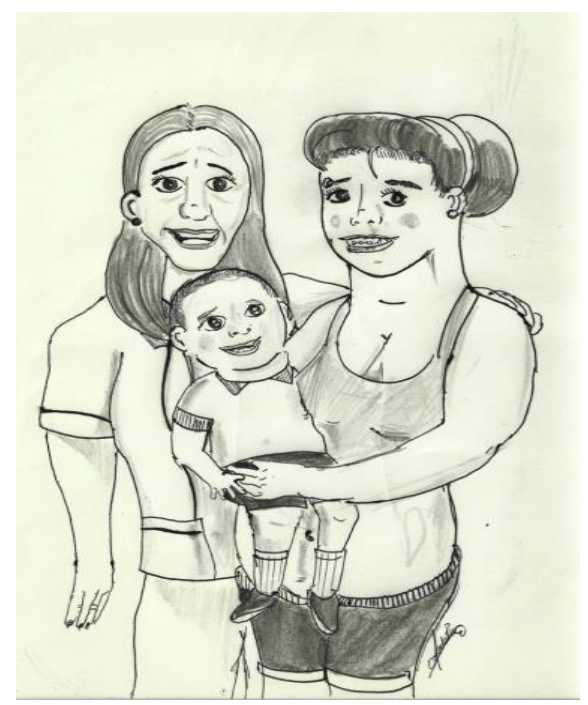

Concibo que las IES han de comprometerse con comunidades específicas y acompañar a las familias de por vida. Solo así se podrá mostrar las ventajas de la continuidad en la salud. En tal sentido, ha de hacerse presencia activa en la zona.
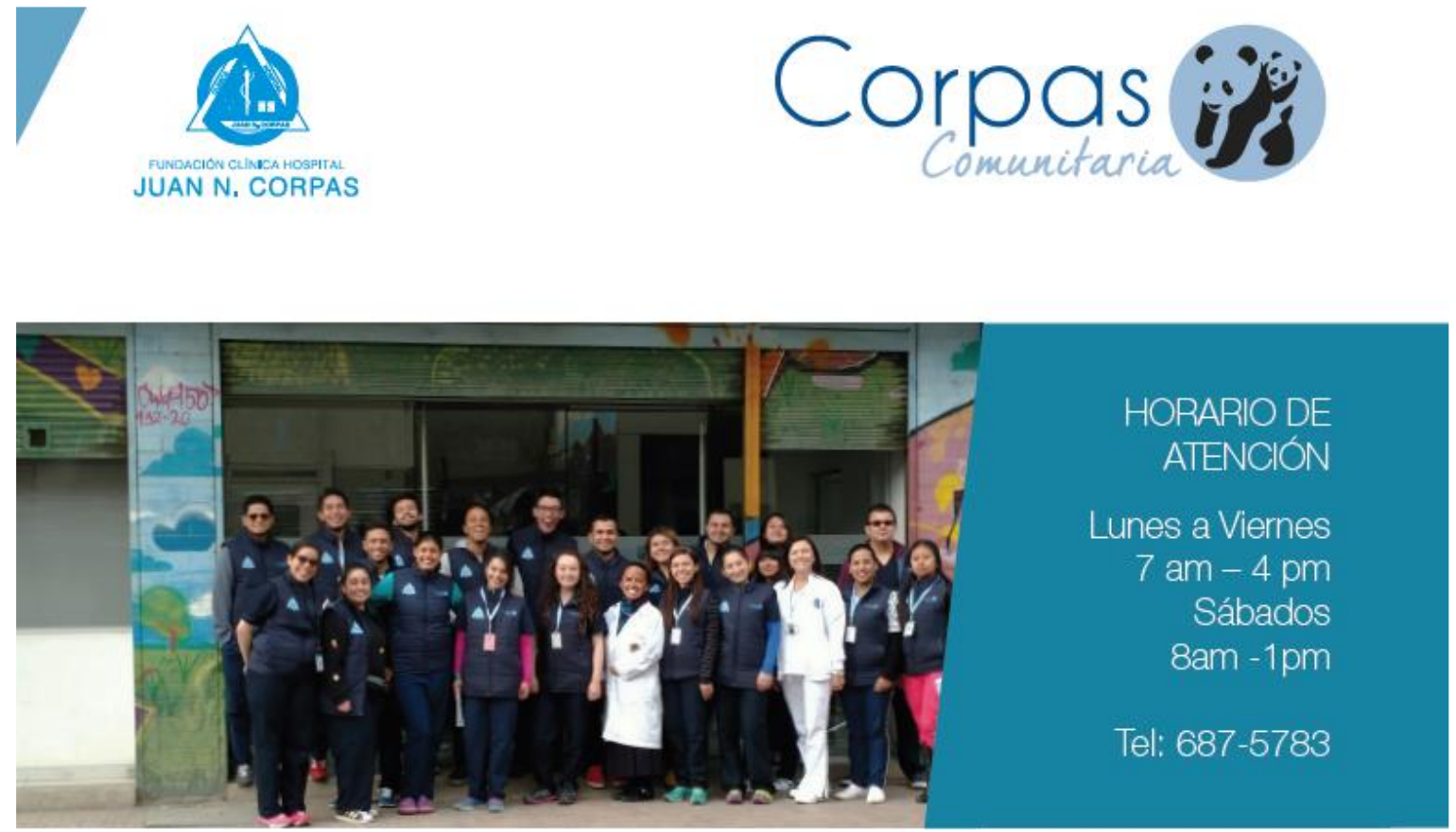

Ha de tenerse un equipo sólidamente conformado que se encargue de establecer las relaciones con la comunidad. 


\section{¿Cómo?}

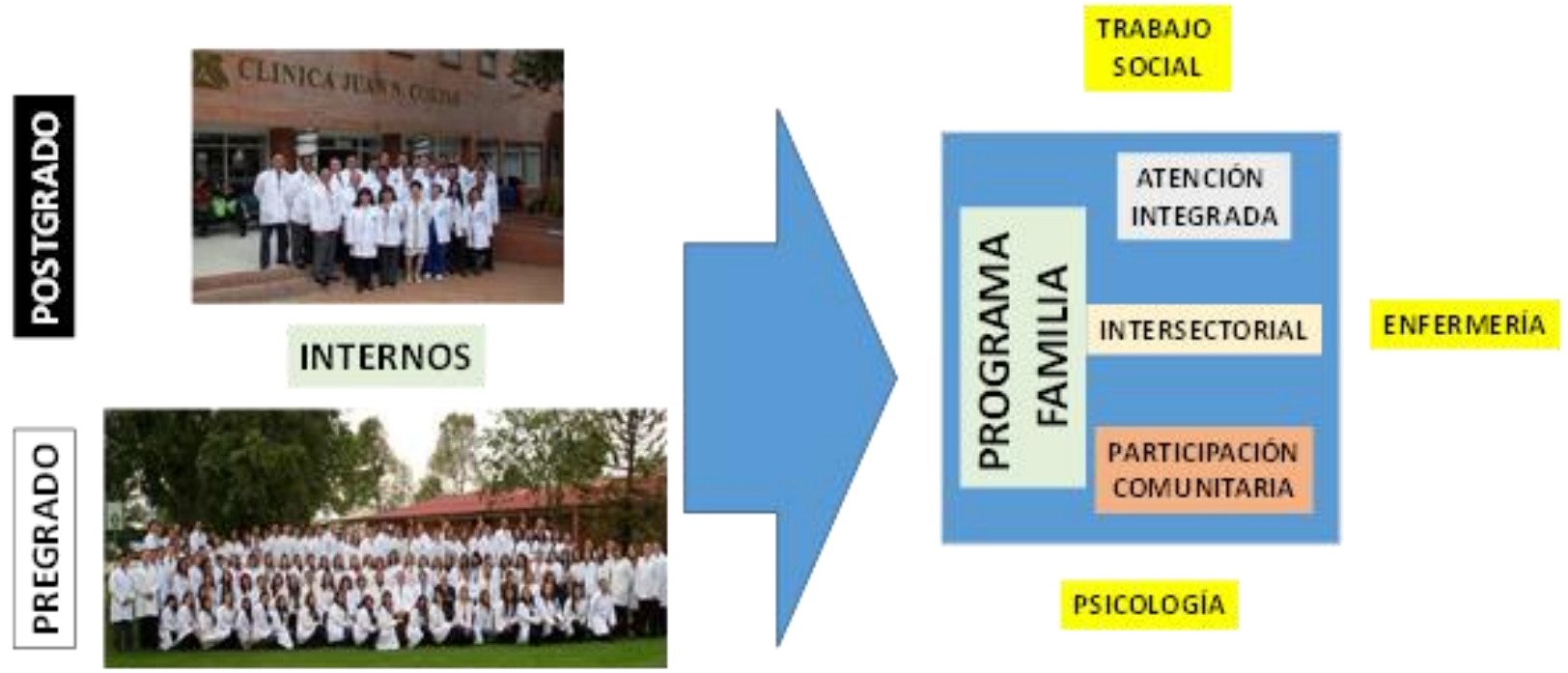

Propongo, y tomo por ejemplo a Medicina, la construcción de un programa de integración en la comunidad que una el pregrado y el posgrado, así como otras profesiones del área de la salud, para llegar a unas familias con las que nos comprometamos de por vida.

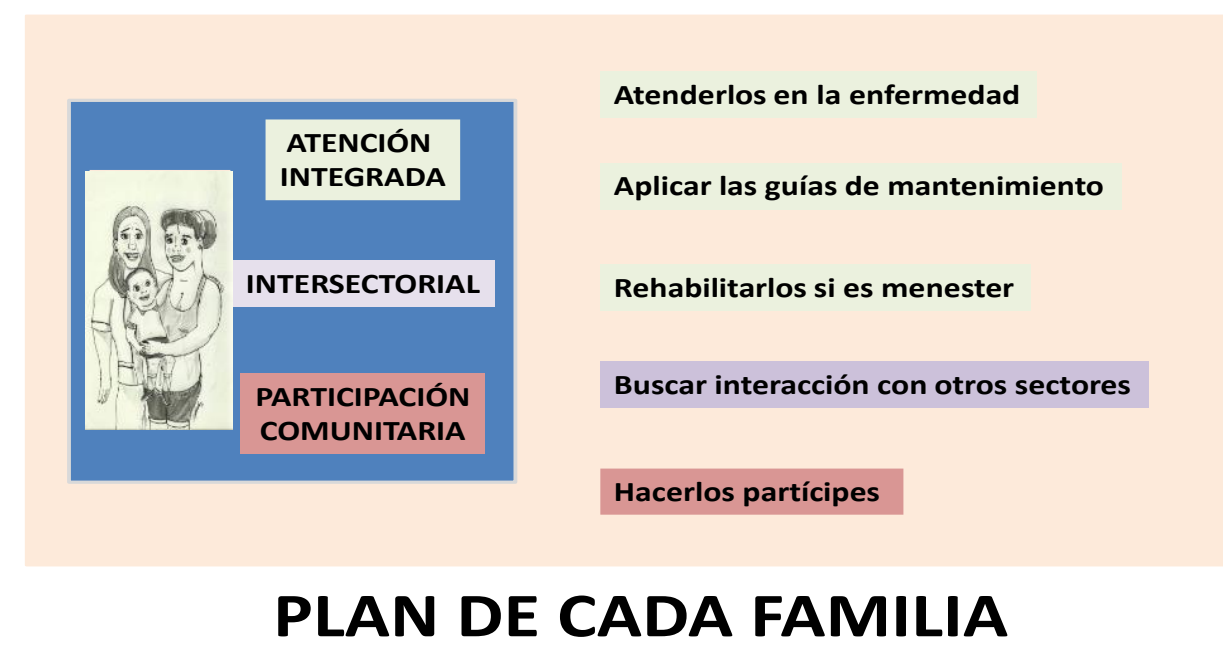

A cada familia le construiremos un plan que nos comprometeremos a ejecutar, plan donde la participación de ellos y el trabajo intersectorial estén presentes. ¿Quiénes hacemos el plan? Los docentes de comunidad que, junto con los estudiantes de pregrado (Medicina) y posgrado (Medicina Familiar), asuman como suyas las familias pertinentes. Cuando digo asuman, hablo de compromiso en donde hacemos el plan para ofrecer el máximo de salud posible a las familia(s) asignada(s). iOjo!, intuyo que los docentes hemos sido preparados para hacer esos planes de salud y seremos medidos por el grado de bienestar aportado a las familias a nuestro cargo. Sé que nos enfrentaremos con situaciones donde necesitamos el concurso de otras profesiones. Por eso sé que debemos atraer a otras profesiones. En claro tengo enfermería, psicología y trabajo social, por ende, el espacio en comunidad donde trabajemos ha de ser lo suficientemente amplio para recibir a dichas áreas. 
Soy consciente de que no podemos comprometernos a ofrecerles a las familias todo lo que le corresponde hacer a las EPS. Pero creo a pesar de ello, el ayudarlos a través del acompañamiento es suficiente y necesario, siendo conscientes de la necesidad de trabajar integrándonos con el Sistema. Hacerles el plan de mantenimiento de la salud, ayudarlos cuando están enfermos, contribuir con su organización comunitaria, buscar a otros sectores, son actividades que sí son posibles.
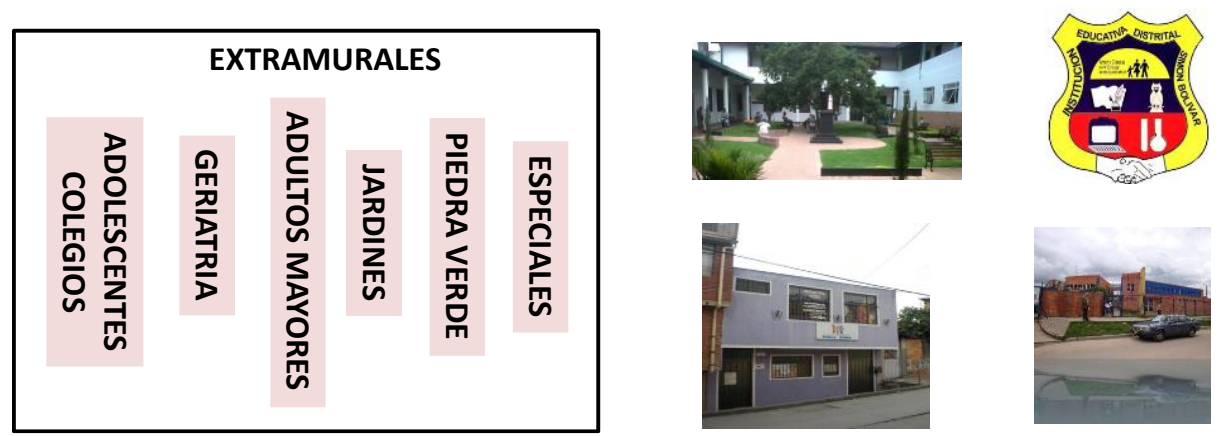

Intuyo el desarrollo de al menos seis programas para comunidades organizadas; algunos de ellos son, por ejemplo, jardines comunitarios, grupos de adultos mayores, colegios, hogares de niños especiales. Una vez más intuyo que es necesario unirnos con otros sectores educativos. Sé que esos escenarios y tales poblaciones nos ofrecen la posibilidad de aprender aspectos específicos tales como la semiología, pero, además, de hacernos sentir las condiciones como viven y proponer alternativas viables para cambiar realidades sociales.

Pero, repito, visualizó a un grupo de personas que nos abren las puertas de la comunidad. Nosotros desde nuestro quehacer y compromiso hacia la comunidad, consolidamos tal integración.
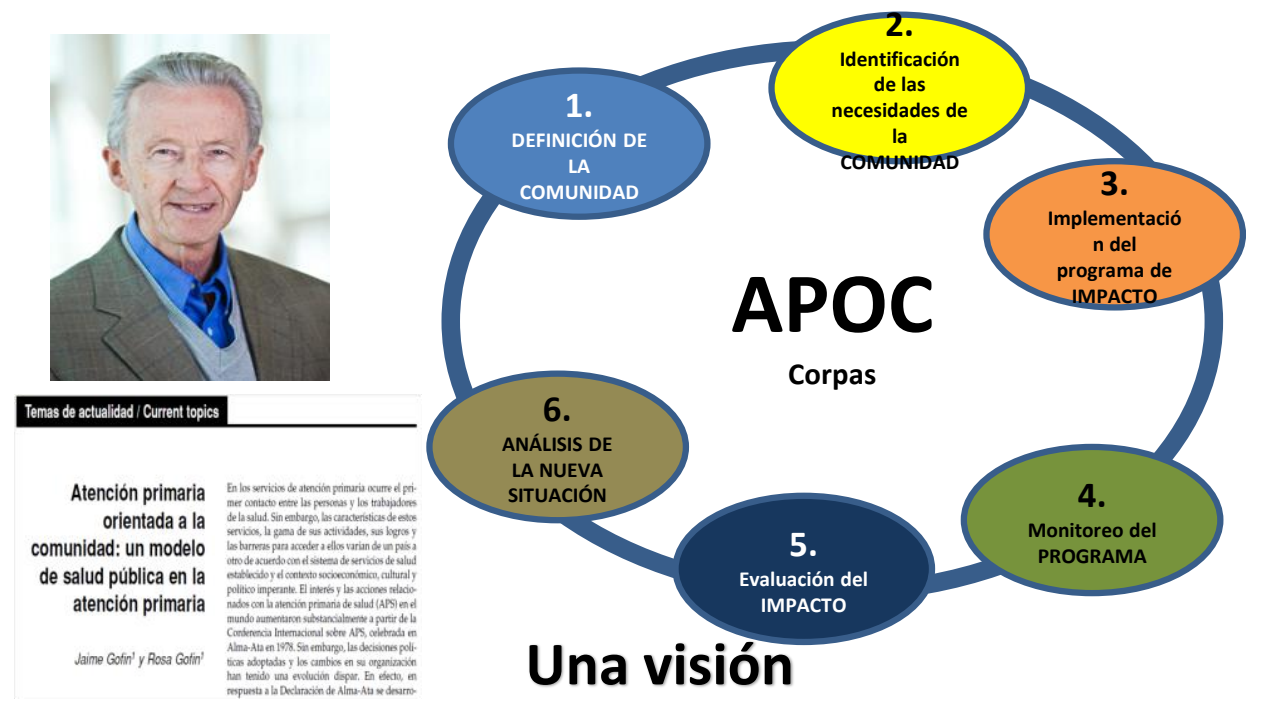

Una estrategia para consolidar este proyecto puede ser el APOC descrito por el doctor Jaime Gofin y su esposa Rosa. Creo que tal estrategia nos abre un camino sencillo y posible, siempre y cuando tengamos el compromiso.

iHay tanto por hacer!

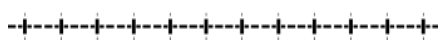

